\title{
Temporal and Spatial Order of Events During the Induction of Cortical Cell Divisions in White Clover by Rhizobium leguminosarum bv. trifolii Inoculation or Localized Cytokinin Addition
}

\author{
Ulrike Mathesius, ${ }^{1}$ Celine Charon, ${ }^{2}$ Barry G. Rolfe, ${ }^{1}$ Adam Kondorosi, ${ }^{2}$ and Martin Crespi ${ }^{2}$ \\ ${ }^{1}$ Plant Microbe Interactions Group, Research School of Biological Sciences, Australian National University \\ (ANU), GPO Box 475, Canberra ACT 2601, Australia; ${ }^{2}$ Institute des Sciences Végétales, Centre National \\ de la Recherche Scientifique, 1 Avenue de la Terrasse, F-91198, Gif sur Yvette Cedex, France \\ Accepted 7 March 2000.
}

\begin{abstract}
We examined the timing and location of several early root responses to Rhizobium leguminosarum bv. trifolii infection, compared with a localized addition of cytokinin in white clover, to study the role of cytokinin in early signaling during nodule initiation. Induction of ENOD40 expression by either rhizobia or cytokinin was similar in timing and location and occurred in nodule progenitor cells in the inner cortex. Inoculation of rhizobia in the mature root failed to induce ENOD40 expression and cortical cell divisions (ccd). Nitrate addition at levels repressing nodule formation inhibited ENOD40 induction by rhizobia but not by cytokinin. ENOD40 expression was not induced by auxin, an auxin transport inhibitor, or an ethylene precursor. In contrast to rhizobia, cytokinin addition was not sufficient to induce a modulation of the auxin flow, the induction of specific chalcone synthase genes, and the accumulation of fluorescent compounds associated with nodule initiation. However, cytokinin addition was sufficient for the localized induction of auxin-induced $\mathrm{GH} 3$ gene expression and the initiation of ccd. Our results suggest that rhizobia induce cytokinin-mediated events in parallel to changes in auxin-related responses during nodule initiation and support a role of ENOD40 in regulating ccd. We propose a model for the interactions of cytokinin with auxin, ENOD40, flavonoids, and nitrate during nodulation.
\end{abstract}

Additional keywords: auxin transport inhibition, fluorescence, GH3: gusA, signal transduction.

Under nitrogen-limiting conditions, soil bacteria of the genera Rhizobium, Bradyrhizobium, Sinorhizobium, Mesorhizobium, and Azorhizobium, generically called rhizobia, enter into a symbiosis with certain legume plants that results in the formation of root nodules. Upon stimulation by flavonoids exuded from legume roots into the soil, rhizobia synthesize signaling molecules that are responsible for nodule formation. These signaling molecules have been identified as lipochitin oligosaccharides (LCOs; Lerouge et al. 1990) and are suffi-

Corresponding author: Barry G. Rolfe; E-mail: Rolfe@ rsbs.anu.edu.au cient to activate the cell cycle machinery necessary for cortical cell divisions (ccd) (Yang et al. 1994), but their mechanism of action is so far unknown (Schultze and Kondorosi 1998). It is likely that LCOs act by perturbing the plant hormone balance because external manipulation of the cytokinin or auxin balance can induce pseudonodules that express nodulin genes in the absence of rhizobia (Bauer et al. 1996; Cooper and Long 1994; Hirsch et al. 1997; Hirsch and Fang 1994).

It has been shown that Rhizobium sp. or LCO inoculation leads to a modulation of auxin transport during nodule formation. First, rhizobia or LCOs induce a rapid (within 5 to $10 \mathrm{~h}$ post inoculation [p.i.]) and local reduction of the expression of an auxin-responsive promoter $(\mathrm{GH} 3)$ fused to the gusA reporter gene in white clover (Mathesius et al. 1998b). These changes in GH3:gusA expression can be mimicked by a synthetic auxin transport inhibitor, NPA ( $\alpha$-naphthylphthalamic acid), and were therefore interpreted to be due to a transient inhibition of polar auxin transport in roots infected by rhizobia (Mathesius et al. 1998b). In vetch, it has been shown that LCOs of nodulating rhizobia reduce the auxin transport capacity in the roots (Boot et al. 1999). Auxin transport inhibition appears to be transient and is followed by an accumulation of GH3:gusA expression in nodule primordium cells (Mathesius et al. 1998b).

Even though it is not known how LCOs interfere with auxin transport, it has been speculated that flavonoids could mediate this effect (Hirsch 1992). This hypothesis is supported by the fact that in white clover certain flavonoids can mimic the action of LCOs on the expression of GH3:gusA (Mathesius et al. 1998b) and that changes in GH3:gusA expression are preceded by the up-regulation of a chalcone synthase (CHS) gene, coding for the first enzyme in the flavonoid pathway, in inner cortical cells underlying the inoculation site of $R$. leguminosarum bv. trifolii (Mathesius et al. 1998a). A specific flavonoid end product, a derivative of 7,4'-dihydroxyflavone (DHF), subsequently accumulates in the inner cortex cells expressing $\mathrm{CHS}$, followed by the accumulation of the isoflavonoid formononetin in nodule primordia (Mathesius et al. 1998a). These changes are specifically induced by clovernodulating rhizobia and their LCOs but not by non-nodulating 
mutants or by foreign rhizobia, suggesting that they are necessary for nodule formation (Mathesius et al. 1998a, 1998b). However, it is likely that one or more other signals apart from auxin are necessary for the induction of ccd during nodule formation, and this study focuses on the possible involvement of cytokinin and the early nodulin gene ENOD40 in nodule initiation in white clover.

There is much circumstantial evidence suggesting that cytokinin is involved in nodule formation (Arora et al. 1959; Bauer et al. 1996; Cooper and Long 1994; Hirsch et al. 1997; Libbenga et al. 1973; Relic et al. 1994; Rodriguez-Barrueco and Bermudez de Castro 1973). Cooper and Long (1994) transferred the Agrobacterium trans-zeatin gene to nodulationdeficient mutants of Sinorhizobium meliloti and showed that synthesis of the cytokinin zeatin by those bacteria was sufficient to induce nodulelike structures in alfalfa at low frequencies. Moreover, LCOs and cytokinins induced similar inner ccd, amyloplast deposition, and expression of early nodulin genes (Bauer et al. 1996; Dehio and deBrujin 1992; Cooper and Long 1994; Fang and Hirsch 1998), suggesting that cytokinins and LCOs may share elements of their signal transduction pathways in the inner cortex. However, so far it is not known how cytokinin is involved in the early signaling events that lead to nodule initiation, and this study aims at elucidating the possible interactions of cytokinin with other early (5 to $60 \mathrm{~h}$ p.i.) signals during nodule initiation.

The ENOD40 gene is an early nodulin gene inducible by both $S$. meliloti and cytokinin in alfalfa (Fang and Hirsch 1998). This gene has been cloned from several legumes (Asad et al. 1994; Corich et al. 1998; Crespi et al. 1994; Kouchi and Hata 1993; Matvienko et al. 1994; Papadopoulou et al. 1996; Vijn et al. 1995; Yang et al. 1993) and from non-legumes (van de Sande et al. 1996; Kouchi et al. 1999). In all legumes examined, ENOD40 mRNA has been localized in dividing and meristematic cells of the nodule primordium. Interestingly, ENOD40 function, like cytokinin action, might be important for cell cycle control in the primordium because overexpression of ENOD40 induces ccd in nitrogen-deprived alfalfa roots in the absence of rhizobia (Charon et al. 1997). In addition, transgenic Medicago truncatula plants over- or underexpressing this gene showed accelerated or perturbed nodulation in response to $S$. meliloti, respectively (Charon et al. 1999).

To provide a more detailed picture of the events leading to nodule initiation in white clover, we have examined the expression patterns of ENOD 40 following R. leguminosarum bv. trifolii inoculation and related them to the concomitant temporal and spatial changes in GH3:gusA expression and flavonoid pathway induction that were previously established (Mathesius et al. 1998a, 1998b). In addition, the effect of localized addition of cytokinin over the first $60 \mathrm{~h}$ after application, the period constituting the earliest root responses to rhizobia, was studied in detail to determine which rhizobia-induced responses are mimicked by cytokinin in white clover. Our results suggest that rhizobia induce cytokinin-mediated events in parallel to changes in auxin-driven gene expression and support a role of ENOD40 in regulating ccd during nodule initiation.

\section{RESULTS}

\section{Expression of ENOD40 during nodule initiation.}

Expression of ENOD4O in white clover roots was studied with whole-mount, in situ hybridization during the early stages of nodule formation after spot inoculation of $R$. leguminosarum bv. trifolii ANU843. For each treatment and time point, three to five roots were analyzed and both FITC (fluorescein isothiocyanate)-labeled and AP (alkaline phosphatase) anti-digoxigenin (DIG) antibodies were used in sequential sections to confirm our results. The sense controls showed no staining for AP (Fig. 1A), whereas in sections viewed under UV, yellow and green autofluorescence resembling FITC fluorescence was seen in the cell walls, especially of xylem and endodermis cells (Fig. 1E). However, no intracellular autofluorescence occurred in cortical cells (Fig. 1E). Autofluorescence was also strong in lateral root primordia, root tips, and mature nodules (data not shown).

Sections of the mock-inoculated roots labeled with antisense ENOD40 probes showed AP activity and FITC fluorescence in the vascular bundle, including the parenchyma and

Fig. 1. In situ hybridization of ENOD40 in white clover root sections during nodule initiation and following treatment with plant growth regulators. An FITC (fluorescein isothiocyanate)-conjugated antibody (visible as intracellular green fluorescence) or an AP (alkaline phosphatase)-conjugated antibody (dark purple staining) was used to detect anti-digoxigenin (DIG)-labeled ENOD40 mRNA. A and E, Sense controls. B-D and F-N, Treated with antisense ENOD40 mRNA. A, No AP staining occurs in roots treated with the sense probe against ENOD40. B, AP staining occurs in the vascular bundle and pericycle (p) of a mock-inoculated root $30 \mathrm{~h}$ post inoculation (p.i.). C, AP staining occurs in an emerging lateral root primordium (lr) of a mockinoculated root in the mature root zone, and is also visible in nondivided cortical cells of the main root located just adjacent to the emerging lateral root primordium (arrows). D, 30 h p.i. with strain ANU843. AP staining is strong in pericycle and yet undivided inner cortical cells (between arrow heads) in front of one of the xylem poles. E, Root section $30 \mathrm{~h}$ p.i. with ANU843, treated with sense probe against ENOD40, shows some yellow autofluorescence in cell walls, especially in the epidermis including the root hairs, the endodermis (e), and xylem poles. No intracellular green fluorescence is visible in the cortex (c). F, Mock-inoculated root $48 \mathrm{~h}$ p.i. Green FITC fluorescence appears in vascular bundle (v), including pericycle. Cell wall autofluorescence also occurs in endodermis (e). G, 30 h p.i. with ANU843. Before cortical cell divisions (ccd) are initiated, intracellular FITC fluorescence is seen in inner cortex cells (c) and pericycle cells (p) in front of one xylem pole (between arrow heads). FITC fluorescence occurs inside cortex and pericycle cells, not just in cell walls as shown in the sense control in E. Autofluorescence occurs in cell walls in the endodermis (e). H, No FITC fluorescence and no divisions are induced in cortex (c) after $60 \mathrm{~h}$ p.i. with ANU843 in the presence of $15 \mathrm{mM}$ nitrate in the growth medium. Weak flu orescence can be seen in pericycle (p) and autofluorescence occurs in cell walls. I, A root treated for $60 \mathrm{~h}$ with $100 \mu \mathrm{M}$ BAP (benzylamino purine) shows strong FITC fluorescence in all inner cortical cells (c) and pericycle cells (p) in a ring around vascular bundle (arrow heads). Some but not all of these cortical cells had divided at this stage. J, FITC fluorescence occurs in cortical cells (c, arrowheads) of a root treated with $100 \mu \mathrm{M}$ BAP for $60 \mathrm{~h}$ in the presence of $15 \mathrm{mM}$ nitrate. No ccd were induced in these roots. Some FITC fluorescence also occurs in pericycle (p). K, AP-stained section of a root $60 \mathrm{~h}$ p.i. with $100 \mu \mathrm{M}$ BAP in the presence of $15 \mathrm{mM}$ nitrate. Staining occurs in pericycle (p) and cortical cells (c; arrowheads). L, No FITC fluorescence and no divisions are induced in cortex $48 \mathrm{~h}$ p.i. with $100 \mu \mathrm{M}$ NPA. Some FITC fluorescence occurs in the pericycle (p). M, No FITC fluorescence and no divisions are induced in cortex $48 \mathrm{~h}$ p.i. with $100 \mu \mathrm{M}$ IAA. N, No FITC fluorescence and no divisions are induced in cortex $48 \mathrm{~h}$ p.i. with $100 \mu \mathrm{M}$ ACC (1-aminocyclopropane-1-carboxylic acid). Some FITC fluorescence is visible in pericycle (p), especially opposite xylem poles (arrowhead indicates one such island of expression). Magnification bars $=(\mathbf{A}, \mathbf{B}, \mathbf{D}, \mathbf{E}, \mathbf{F}, \mathbf{L}, \mathbf{M}) 100 \mu \mathrm{m},(\mathbf{H}, \mathbf{I}) 75 \mu \mathrm{m},(\mathbf{C}, \mathbf{G}, \mathbf{J}, \mathbf{K}, \mathbf{N}) 50 \mu \mathrm{m}$. 
pericycle (Fig. 1B and F, respectively), suggesting the presence of a background ENOD4O expression in these tissues. In addition, ENOD40 expression was detected in developing lateral root primordia and in cortical cells of the main root adja- cent to the emerging lateral root primordium in mockinoculated roots (Fig. 1C).

In roots spot-inoculated with strain ANU843 at the zone of emerging root hairs, AP activity and FITC fluorescence
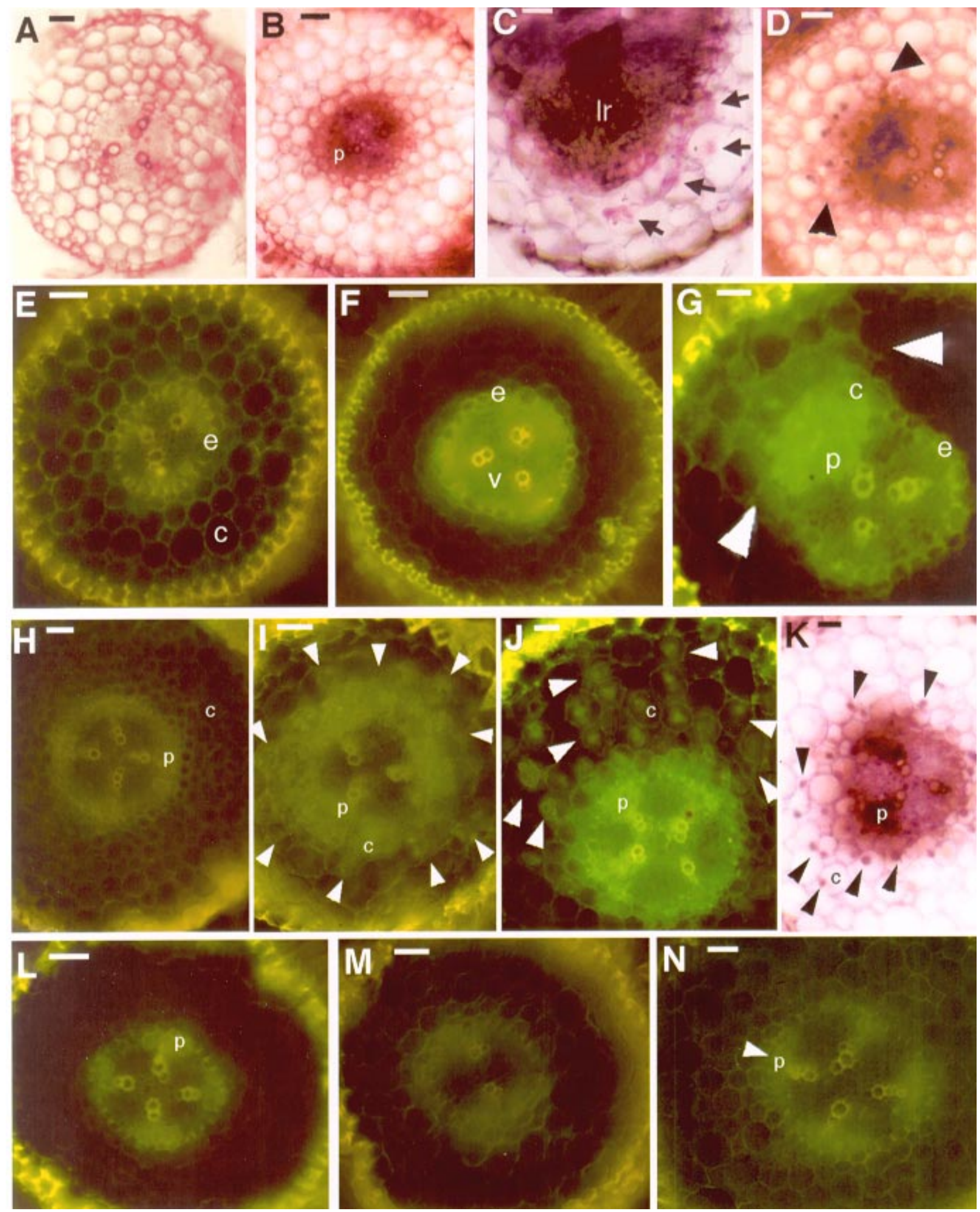
were detected in pericycle cells opposite the xylem poles between 3 and $24 \mathrm{~h}$ p.i. in all examined sections (Table 1). This expression pattern was similar to that in the untreated roots but the expression in inoculated roots was stronger in the pericycle and increased in intensity over time. After 30 h p.i., before cell divisions in the inner cortex had started, strong AP activity and FITC fluorescence could be seen in inner cortex and pericycle cells opposite one of the xylem poles (Fig. 1D and G, respectively). After $40 \mathrm{~h}$ p.i., AP activity and FITC fluorescence were enhanced in inner cortex cells in front of one of the xylem poles where the first inner ccd occurred (Table 1). Between 50 and $70 \mathrm{~h}$ p.i., a small nodule primordium formed that showed both AP activity and FITC fluorescence (Table 1). One-weekold nodule primordia showed AP staining in the developing vascular tissue (data not shown). FITC fluorescence occurred throughout the nodule at this time point, but this could not be distinguished from autofluorescence that oc- curred in nodules incubated with the ENOD40 sense probe (data not shown).

To confirm the specificity of the observed induction we inoculated strain ANU845, which is derived from strain ANU843 but does not contain any nodulation genes. No ENOD40 expression or ccd were induced in cortical cells by strain ANU845 within $60 \mathrm{~h}$ p.i. (Table 1). Inoculation of an $S$. meliloti strain (ANU1080), which nodulates Medicago species but not clover, also failed to induce ENOD40 expression and ccd in the cortex (Table 1). When strain ANU843 was spot inoculated in the mature root zone ( $3 \mathrm{~cm}$ above the root tip) and roots sectioned after 16, 24, and $48 \mathrm{~h}$ p.i., ENOD40 expression was seen in the pericycle but no, or only very little, expression could be detected in the cortex (Table 1). In contrast to spot inoculations at the zone of emerging root hairs, no ccd were induced by strain ANU843 in the mature root. As an additional control, $15 \mathrm{mM}$ nitrate was added to the plant growth medium, which was sufficient to inhibit ccd. None of

Table 1. ENOD40 expression in white clover roots in response to different stimuli

\begin{tabular}{|c|c|c|c|c|c|}
\hline Inoculum & Nitrate added (mM) & $\begin{array}{c}\text { Time point } \\
\text { (h post inoculation) }\end{array}$ & $\begin{array}{l}\text { Expression } \\
\text { in pericycle }\end{array}$ & Expression in cortex & Cortical cell divisions \\
\hline Control, zone $1^{\mathrm{a}}$ & 0 & $0-60$ & $+^{\mathrm{b}}$ & $-^{\mathrm{b}}$ & $-^{b}$ \\
\hline Control, zone 1 & 15 & $0-60$ & + & - & - \\
\hline Control, zone 2 & 0 & $0-60$ & + & - & - \\
\hline ANU843, zone 1 & 0 & $0-30$ & ++ & - & - \\
\hline ANU843, zone 1 & 0 & $30-60$ & +++ & +++ & + \\
\hline ANU843, zone 2 & 0 & 48 & + & - & - \\
\hline ANU843, zone 1 & 15 & 48 & + & - & - \\
\hline ANU845, zone 1 & 0 & 60 & + & - & - \\
\hline ANU1080, zone 1 & 0 & 60 & + & - & - \\
\hline BAP $(100 \mu \mathrm{M})$, zone 1 & 0 & $0-30$ & ++ & - & - \\
\hline BAP $(100 \mu \mathrm{M})$, zone 1 & 0 & $48-60$ & ++ & ++ & + \\
\hline BAP $(100 \mu \mathrm{M})$, zone 2 & 0 & 60 & + & + & + \\
\hline BAP $(100 \mu \mathrm{M})$, zone 1 & 15 & 60 & + & + & - \\
\hline NPA $(100 \mu \mathrm{M})$, zone 1 & 0 & $0-48$ & + & - & - \\
\hline ACC $(100 \mu \mathrm{M})$, zone 1 & 0 & $0-48$ & + & - & - \\
\hline IAA $(100 \mu \mathrm{M})$, zone 1 & 0 & $0-48$ & + & - & - \\
\hline
\end{tabular}

${ }^{a}$ Zone 1 was at the zone of emerging root hairs, zone 2 was $3 \mathrm{~cm}$ above the root tip in the mature root.

${ }^{\mathrm{b}}$ For every treatment, a minimum of five roots were examined. Where negative responses were recorded, none of the roots showed a response. Where positive responses were recorded, at least four of five roots showed a positive response. Number of + indicates staining intensity of AP (alkaline phosphatase)- or FITC (fluorescein isothiocyanate)-stained roots. BAP = benzylamino purine; NPA $=\alpha$-naphthylphthalamic acid; ACC $=1$ aminocyclopropane-1-carboxylic acid; IAA = indole-3-acetic acid.

Fig. 2. Effects of cytokinin on (A-E) cell division, (G-M) transgene expression, and (N-P) fluorescence accumulation in white clover roots. A-F, Sections were stained with toluidine blue. G-M, Sections were stained for $\beta$-glucuronidase (GUS) expression. N-P, Sections were stained with DPBA (diphenylboric acid-2-aminoethylester) preceding fluorescence detection to visualize fluorescent flavonoid compounds in tissue. G-M, Arrowheads indicate site of cytokinin application. A, Treatment (14 day) with BAP (benzylamino purine; $1 \mu \mathrm{M})$ does not induce cortical cell divisions (ccd). B, Treatment (14 day) with $10 \mu \mathrm{M}$ BAP leads to a ring of ccd in inner cortex (c, arrowheads). Divisions are also visible in the pericycle (p). C, Treatment $(48 \mathrm{~h})$ with $100 \mu \mathrm{M}$ BAP leads to anticlinal divisions in inner cortex (c, arrowheads). Some divisions also occur in pericycle (p), but not in endodermis (e). D, Treatment (72 h) with $100 \mu \mathrm{M}$ BAP showing more extended anticlinal cortical divisions (c, arrowheads) as well as periclinal pericycle (p) divisions. E, After treatment (1 week) with $100 \mu \mathrm{M}$ BAP, a nodule primordium-like structure (n) has formed in cortex. F, A 1-week-old nodule primordium (n) induced by Rhizobium leguminosarum bv. trifolii. G, Treatment $(5 \mathrm{~h})$ with $100 \mu \mathrm{M}$ BAP does not change GH3:gusA expression, compared with mock-inoculated roots that show a similar expression in the vascular bundle as shown here. H, Treatment $(24 \mathrm{~h})$ with $100 \mu \mathrm{M}$ BAP does not affect GH3:gusA expression. I, Treatment (48 h) with $100 \mu \mathrm{M}$ BAP enhances GH3:gusA expression at application site in vascular bundle and cortex (arrowhead). No cell divisions had occurred at this stage. J, GH3:gusA expression occurs in two nodule primordium-like structures (arrowheads) induced by $100 \mu \mathrm{M}$ BAP after 1 week. BAP was applied at one site only but induced two primordia. K, Treatment (24 h) with $100 \mu \mathrm{M}$ BAP induces CHS1:gusA expression at site of application (arrowhead) in inner cortical and vascular tissues. L, Treatment (5 h) with $100 \mu \mathrm{M}$ BAP induces CHS2:gusA expression at site of application (arrowhead) in vascular bundle and inner cortex. M, Treatment ( $24 \mathrm{~h}$ ) with $100 \mu \mathrm{M}$ BAP fails to markedly induce CHS3: gusA expression at site of application (arrowhead). Response in root shown was strongest response of any treated root. N, Treatment (48 h) with $100 \mu \mathrm{M}$ BAP induces a blue fluorescence in inner cortex and pericycle cells that did not change color after DPBA application. O, Treatment ( 7 day) with $100 \mu \mathrm{M}$ BAP leads to inner ccd (arrowheads indicate plane of division of two inner cortical cells) that contain a blue vacuolar fluorescence. Yellow fluorescence occurs in a group of dividing pericycle cells (p). P, Treatment ( 8 day) with $100 \mu \mathrm{M}$ BAP induces nodule primordia-like structures with blue fluorescence occurring in dividing cells in nodule primordium (n). Undivided, surrounding cortical cells contain an orange DPBA-induced fluorescence (arrowheads). Yellow fluorescence occurs in dividing pericycle cells (p). Magnifications bars = $(\mathbf{A}, \mathbf{B}) 75 \mu \mathrm{m},(\mathbf{C}, \mathbf{D}, \mathbf{P}) 50 \mu \mathrm{m},(\mathbf{E}, \mathbf{F}) 100 \mu \mathrm{m},(\mathbf{N}, \mathbf{O}) 25 \mu \mathrm{m} ;(\mathbf{G}-\mathbf{M}) 1 \mathrm{~mm}$. 
the roots spot inoculated with strain ANU843 in the presence of nitrate showed ENOD40 expression in the cortex, while some expression was seen in the pericycle (Fig. 1H). The results are summarized in Table 1.
The effect of cytokinin on ccd in white clover.

To determine the effective concentrations of cytokinin in white clover, the cytokinin BAP (benzylamino purine) was applied in agar blocks to the zone of emerging root hairs at
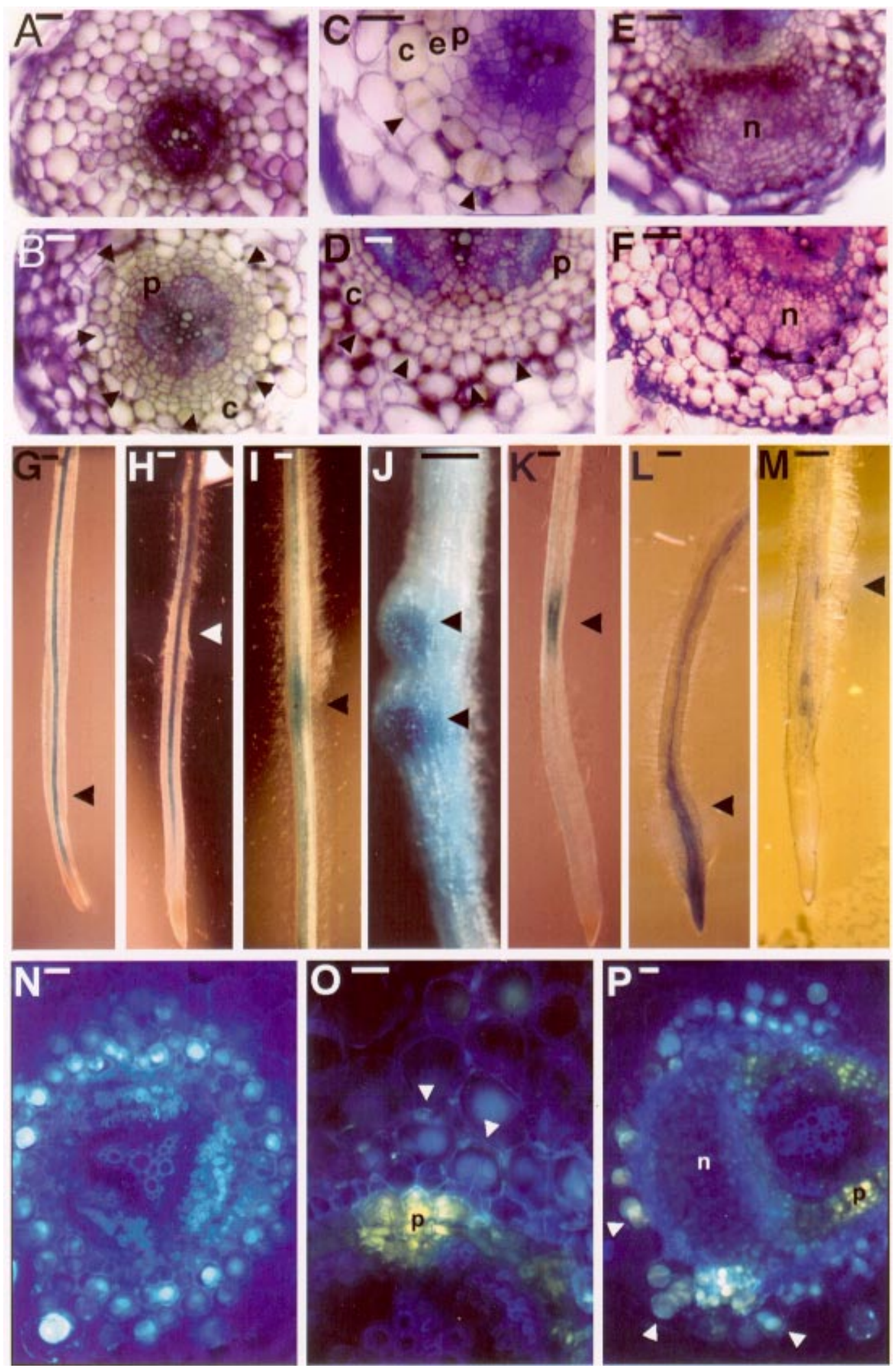
concentrations of 1 to $100 \mu \mathrm{M}$. After 2 weeks, anticlinal inner ccd were observed in none of 20 roots treated with $1 \mu \mathrm{M}$ BAP (Fig. 2A), in 16 of 20 roots treated with $10 \mu \mathrm{M}$ BAP (Fig. 2B), and in 19 out of 20 roots treated with $100 \mu \mathrm{M}$ BAP (Fig. 2CE). Some periclinal divisions also occurred in the pericycle (Fig. 2B-D). Whereas $10 \mu \mathrm{M}$ BAP induced only limited divisions in the inner cortex (Fig. 2B), only $100 \mu \mathrm{M}$ BAP led to the formation of nodule primordia-like structures (Fig. 2E). Therefore, localized application of $100 \mu \mathrm{M}$ BAP was used in all subsequent experiments, as this most closely resembled the nodule primordia induced by $R$. leguminosarum bv. trifolii (Fig. 1F).

In a time course experiment, root sections were examined after $100 \mu \mathrm{M}$ BAP treatment. No ccd were detected between 12 and $30 \mathrm{~h}$ p.i. The first anticlinal ccd could be detected at 48 h p.i. in two of eight roots (Fig. 2C). Between 48 and 72 h, the number of divided inner cortex cells increased, and ccd were seen in two of eight roots (Fig. 2D). After 1 week of incubation, two of 10 roots contained nodule primordia-like structures derived from cortical cell divisions (Fig. 2E), similar to $R$. leguminosarum bv. trifolii-induced nodule primordia of equivalent developmental stages (Fig. 1F). In the other eight BAP-treated roots, numerous divided inner cortex cells were seen in a ring around the vascular bundle, many of which had already divided several times in front of a xylem pole (similar to Figure 2B).

\section{Expression of ENOD40 in response to cytokinin and other plant growth regulators.}

A concentration of $100 \mu \mathrm{M}$ of the cytokinin BAP, the auxin IAA (indole-3-acetic acid), the ethylene precursor ACC (1aminocyclopropane-1-carboxylic acid), or the auxin transport inhibitor NPA was applied individually to roots by placing agar cubes of $2 \mathrm{~mm}$ side length containing each hormone at the zone of emerging root hairs. Roots were incubated for 16 , 24 , or $48 \mathrm{~h}$ and, in the case of cytokinin, additionally for $30 \mathrm{~h}$ and $60 \mathrm{~h}$. Three to five roots were incubated for each treatment and each time point, and ENOD40 was detected with either the FITC- or the AP-conjugated antibody in sections of each root as mentioned above. As negative controls, roots were treated with agar blocks not containing any hormones. As before, the negative controls showed expression of $E N O D 40$ in the parenchyma and pericycle of the vascular bundle, but not in the cortex (as shown in Figure 1B and F). After treatment with BAP, enhanced amounts of ENOD4O transcripts were detected in the pericycle opposite the xylem poles after 16, 24, and $30 \mathrm{~h}$ p.i. (Table 1). At $48 \mathrm{~h}$ p.i., ENOD40 expression occurred in non-divided and just-divided inner cortex cells. Expression was either concentrated opposite only one or two xylem poles or occurred as a symmetric ring of expression around the vascular bundle (Fig. 1I). After $60 \mathrm{~h}$, ENOD40 expression was located in actively dividing inner cortex cells and in the pericycle. BAP treatment in the mature root zone ( $3 \mathrm{~cm}$ above the root tip) led to induction of ccd and ENOD40 expression in inner cortical cells similar to treatment with BAP in the zone of emerging root hairs (Table 1). When $15 \mathrm{mM}$ nitrate was added to the plant growth medium, ENOD40 expression was seen in cortical cells following BAP treatment after $60 \mathrm{~h}$ p.i. (Fig. $1 \mathrm{~J}$ and K), but no ccd were induced in any of the roots. Treatment of roots with NPA (Fig. 1L), IAA (Fig. 1M), or ACC (Fig. 1N) did not lead to induction of ENOD4O expression in the cortex and no ccd were induced within $48 \mathrm{~h}$. However, some ENOD40 expression was visible in the pericycle (Fig. 1L-N; Table 1).

\section{Effect of cytokinin on CHS:gusA and GH3:gusA expression and on fluorescence accumulation.}

If cytokinin is involved in the early signaling events induced by rhizobia, it may also be responsible for some of the effects seen after rhizobia inoculation on legume roots. Differences in both timing and location of the root responses to cytokinin $(100 \mu \mathrm{M})$ and $R$. leguminosarum bv. trifolii (strain ANU843) inoculation were found (Table 2). BAP addition did not affect GH3:gusA expression, compared with mockinoculated roots after 2, 5, and 24 h of BAP application (Fig. $2 \mathrm{G}$ and $\mathrm{H}$; Table 2), in contrast to a local down-regulation of GH3: gusA expression following R. leguminosarum bv. trifolii inoculation (Table 2; Mathesius et al. 1998b). After 48 h, enhanced GH3:gusA expression occurred in the vascular bundle and inner cortex at the site of BAP application (Fig. 2I). After

Table 2.. Effect of local BAP (benzylamino purine) addition compared with effect of Rhizobium leguminosarum bv. trifolii (strain ANU843) spot inoculation on expression of GH3:gusA, CHS1:gusA, CHS2:gusA, and CHS3:gusA in transgenic white clover roots

\begin{tabular}{lccccc}
\hline Transgene & Incubation time $(\mathbf{h})^{\mathbf{a}}$ & BAP $(\mathbf{1 0 0} \boldsymbol{\mu M})$ & Site of response after BAP addition & ANU843 & $\begin{array}{c}\text { Site of response after ANU843 } \\
\text { inoculation }\end{array}$ \\
\hline GH3: gusA & $2(1)$ & $0 / 8^{\mathrm{b}}$ & - & $0 / 10$ & - \\
GH3: gusA & 5 & $0 / 5$ & - & $3 / 29$ & Stele \\
GH3: gusA & 24 & $0 / 17$ & - & $18 / 37$ & whole cortex \\
GH3: gusA & 48 & $12 / 18$ & Stele $^{\mathrm{c}}$ and inner cortex & $14 / 20$ & Inner cortex \\
CHS1: gusA & $2(3)$ & $0 / 10$ & - & $0 / 10$ & - \\
CHS1: gusA & 5 & $2 / 9$ & Stele $^{\mathrm{c}}$ and inner cortex & $6 / 10$ & Outer cortex \\
CHS1: gusA & $24 / 14$ & Stele $^{\mathrm{c}}$ and inner cortex & $15 / 24$ & Outer cortex \\
CHS2: gusA & $2(3)$ & $0 / 6$ & - & $0 / 10$ & - \\
CHS2: gusA & 5 & $3 / 5$ & Inner cortex & $0 / 17$ & - \\
CHS2: gusA & $24(20)$ & $0 / 9$ & - & $2 / 21$ & Inner and middle cortex \\
CHS3: gusA & $2(3)$ & $0 / 10$ & - & $2 / 12$ & Inner cortex \\
CHS3: gusA & 5 & $0 / 4$ & - & $5 / 12$ & Inner cortex \\
CHS3: gusA & $24(20)$ & $0 / 5$ & Inner cortex \\
\hline
\end{tabular}

${ }^{a}$ Numbers in brackets indicate time point analyzed in response to $R$. leguminosarum bv. trifolii inoculation, if different from time point analyzed in response to BAP.

${ }^{\mathrm{b}}$ Numbers of roots responding with changes in transgene expression (determined by visual examination of $\beta$-glucuronidase [GUS]-stained roots) out of the total number of tested roots. Data on effect of ANU843 inoculation on GH3: gusA expression are from Mathesius et al. (1998b).

${ }^{c}$ Expressing tissues in the stele include pericycle and parenchyma. 
1 week, nodule primordia-like structures had formed that strongly expressed GH3:gusA in the first dividing cells (Fig. $2 \mathrm{~J}$ ), similar to the expression in R. leguminosarum bv. trifolii induced nodule primordia (Table 2; Mathesius et al. 1998b). BAP induced CHS1:gusA expression after 5 and $24 \mathrm{~h}$ in the vascular bundle and inner cortex (Fig. $2 \mathrm{~K}$ ), in contrast to CHS1:gusA expression in the epidermis and outer cortex after $R$. leguminosarum bv. trifolii inoculation (Table 2). CHS2:gusA expression was transiently enhanced in the vascular bundle after $5 \mathrm{~h}$ of treatment with BAP (Fig. 2L). This was more rapid than the induction in $R$. leguminosarum bv. trifolii-inoculated roots (after $10 \mathrm{~h}$ p.i.; Table 2). After $24 \mathrm{~h}$ of BAP treatment, no response could be seen in CHS2:gusA transgenic plants. No local CHS3:gusA expression was seen after BAP application (Fig. 2M), in contrast to the strong and local induction of CHS3:gusA after $R$. leguminosarum bv. trifolii inoculation (Table 2; Mathesius et al. 1998a).

When fresh root sections of BAP-treated roots were viewed under a fluorescence microscope for detection of fluorescent flavonoids, blue intracellular fluorescence was seen in inner cortical cells. Fluorescence accumulation in inner cortex cells started at $24 \mathrm{~h}$ p.i. in undivided inner cortex cells (Fig. 2N). The blue fluorescence color did not change after application of the flavonoid-specific dye, DPBA (diphenylboric acid-2aminoethylester), in contrast to induction of orange fluorescence by DPBA in $R$. leguminosarum bv. trifolii-inoculated roots. This orange fluorescence was shown to be due to the presence of a DHF derivative (Mathesius et al. 1998a). After $48 \mathrm{~h}$, the first ccd occurred and the dividing cells contained a blue fluorescence (Fig. 2O). After 1 week, the nodule primordium-like structures fluoresced blue and were surrounded by orange fluorescent outer cortex cells (Fig. 2P), similar to the fluorescence pattern seen in R. leguminosarum bv. trifolii induced nodule primordia (Mathesius et al. 1998a). Table 2 summarizes the various similarities and contrasting findings observed with cytokinin application and $R$. leguminosarum bv. trifolii inoculation with the different transgenic clover plants.

\section{DISCUSSION}

Cytokinin is an insufficient mediator of $R$. leguminosarum $b v$. trifolii-induced root responses in white clover.

In this study we have determined the temporal and spatial sequence of responses that occur in white clover roots in response to $R$. leguminosarum bv. trifolii and cytokinin (Fig. 3A). Localized application of cytokinin was sufficient to induce ccd that expressed ENOD4O and GH3:gusA between 48 and $60 \mathrm{~h}$ p.i., similar to the effect of $R$. leguminosarum bv. trifolii inoculation. However, cytokinin-induced ENOD4O expression was more symmetrically distributed around the inner cortex than $R$. leguminosarum bv. trifolii-induced expression, which was concentrated strictly opposite one xylem pole in the inner cortex. Moreover, cytokinin addition could not induce a number of early root responses to $R$. leguminosarum bv. trifolii infection such as (i) a transient down-regulation of GH3:gusA expression, (ii) CHS1:gusA expression in epidermis and outer cortex and CHS2:gusA and CHS3:gusA in the inner cortex, and (iii) the accumulation of the orange fluorescent DHF derivative in inner cortex cells preceding nodule primordium initiation (Table 2). We conclude that cytokinin is an insufficient mediator for $R$. leguminosarum bv. trifolii induced ccd. Most likely, auxin-related root responses occur separately from cytokinin-induced responses during nodule initiation. Considering that auxin and cytokinin have separate but synergistic effects on activation of the cell cycle (John et al. 1993; Zhang et al. 1996), it appears that rhizobia induce a simultaneous modulation of auxin and cytokinin levels and/or sensitivity to achieve the initiation of ccd (see Figure 3B).

Even though cytokinin alone might not mediate ccd by $R$. leguminosarum bv. trifolii, external application of cytokinin at high concentration $(100 \mu \mathrm{M})$ was sufficient to induce ccd. It is possible that high external concentrations of cytokinin affect auxin levels in the root by a different mechanism than $R$. leguminosarum bv. trifolii does. For example, cytokinin can increase auxin levels by inhibiting IAA oxidase (Hare and van Staden 1997) and this could explain why cytokinin application led to high GH3:gusA expression in dividing cortical cells (see Figure 2I, J). In contrast, $R$. leguminosarum bv. trifolii could affect auxin transport and accumulation via the induction of specific flavonoids, which could act as auxin transport inhibitors (Mathesius et al. 1998b) or IAA oxidase regulators (Schneider and Wightman 1974; Fig. 3B). The action of flavonoids could therefore substitute for the action of high external cytokinin concentrations on auxin levels and subsequently on the induction of ccd.

\section{Expression of ENOD40 marks progenitor cells of a nodule primordium.}

ENOD40 was expressed in inner cortical cells underlying the spot inoculation site before these cells divide in white clover (Figs. 1D, 1G, and 3A). To our knowledge, this is the first report of ENOD4O induction in nodule progenitor cells in the inner cortex, supporting the hypothesis that ENOD40 could have a role in preparation of cortical cells for division. In alfalfa and Sesbania rostrata, ENOD4O expression occurs in outer cortical and epidermis cells preceding ccd (Fang and Hirsch 1998; Corich et al. 1998), suggesting an additional role of ENOD40 during early infection. Several other studies have shown that ENOD4O expression occurs in already divided cortical cells and nodule primordia in various species (Asad et al. 1994; Crespi et al. 1994; Corich et al. 1998; Kouchi and Hata 1993; Yang et al. 1993). In white clover, ENOD40 expression was correlated with the induction of ccd under a range of conditions: cytokinin addition and $R$. leguminosarum bv. trifolii inoculation in the zone of emerging root hairs induced both ENOD4O expression and divisions in the inner cortex, whereas $R$. leguminosarum bv. trifolii inoculations in the mature root zone or treatment with NPA, IAA, or ACC, failed to induce ENOD40 expression and ccd (Table 1). Accordingly, over-expression of ENOD40 in alfalfa leads to spontaneous ccd in the absence of rhizobia (Charon et al. 1997). Those results are also consistent with studies in alfalfa, where auxin, ethylene, gibberellic acid, and abscisic acid failed to induce ENOD40 expression (Fang and Hirsch 1998; Hirsch et al. 1997). However, NPA led to ccd and ENOD4O expression in alfalfa with whole-root treatments (Fang and Hirsch 1998).

Our results show that ENOD40 expression in cortical cells is not sufficient for ccd because, in the presence of nitrate, ENOD40 expression occurred in response to cytokinin, but no ccd were induced (see Fig. 1J, 1K). This is consistent with the 
inhibition of ccd in ENOD40-over-expressing plants in the presence of nitrate (Charon et al. 1997; see below). Similarly, ENOD40 expression in the pericycle, which has been found in many species to precede ccd (Asad et al. 1994; Fang and Hirsch 1998; Yang et al. 1993) also appears insufficient for nodule initiation, because pericycle cells express ENOD4O (although at weaker levels) in mock-inoculated roots, in response to NPA and ACC (Fig. $1 \mathrm{~L}, \mathrm{~N}$ ) and to non-mitogenic chitin derivatives in soybean (Minami et al. 1996).

It is most likely that ENOD40 expression is necessary for ccd to proceed, but that other events, for example, changes in auxin and cytokinin, as indicated in Figure 3B, are necessary in addition to ENOD4O induction. So far, it is not known by which mechanism ENOD 40 could activate cell division. The possibility that a putative ENOD4O peptide modulates auxin levels (van de Sande et al. 1996) could not be confirmed with microtargeting as a means to introduce this peptide into white clover plants expressing the GH3:gusA construct (Mathesius et al. 1998b). Nevertheless, bombardment of an ENOD40 DNA construct spanning the region corresponding to this small ORF could elicit ccd in alfalfa roots (Charon et al. 1997).

\section{The site of inoculation and presence of nitrate determine responsiveness to Rhizobium spp.}

In a recent study we showed that $R$. leguminosarum bv. trifolii inoculation in the mature root zone failed to induce specific root responses such as the expression of specific CHS genes, a modulation of auxin flow, an accumulation of fluorescent compounds, and nodule initiation (Mathesius et al. 2000). This was similar to the absence of ENOD40 induction after $R$. leguminosarum bv. trifolii inoculation in this region (Table 1), even though BAP inoculation in the mature root can induce both ENOD4O and ccd. Hence, cortical cells in the mature root are not insensitive to division or signal perception per se, but LCO signal transduction is probably blocked in this region. Interestingly, expression of ENOD40 occurred in mature cortical cells adjacent to emerging lateral roots (Fig. 1C). These cells also show the above-mentioned root responses, and $R$. leguminosarum bv. trifolii inoculation can result in nodule formation adjacent to lateral roots, supporting the hypothesis that rhizobia can induce nodules in cortical cells activated during lateral root development (Mathesius et al. 2000).

The data presented here show that nitrate inhibits both the induction of ENOD 40 and ccd by R. leguminosarum bv. trifo- lii. However, nitrate inhibits cytokinin-mediated ccd without affecting ENOD40 induction. Inhibition could take place either downstream of ENOD40 expression or during the proposed modulation of auxin levels occurring during nodule initiation. Recently, it was reported that nitrate activates the same response pathways in Arabidopsis as auxin (Zhang et al. 1999) and cytokinin (Taniguchi et al. 1998). These results suggest that both auxin and cytokinin mediate certain nitrate responses. Therefore, we suggest that nitrate might exert its inhibitory effect during nodule initiation by a modulation of both auxin and cytokinin signaling pathways (Fig. 3B).

Other studies also confirmed that nitrate inhibits ccd by cytokinin (Bauer et al. 1996; Cooper and Long 1994). However, in alfalfa, nitrate also inhibited the induction of $E N O D 12 A$ by cytokinin. The reason for these different results could be that the first detection of ENOD12A is in the already divided inner cortex, whereas ENOD4O was detected in predividing cells. Therefore, ENOD40 induction may precede the inhibitory effect of nitrate on ccd (Fig. 3B).

\section{What determines the site of nodule initiation?}

A comparison of the perceived location of auxin (Fig. 3A; Mathesius et al. 1998b) and cytokinin action before the initiation of ccd shows that all cortex cells display high auxin levels whereas only the inner cortex cells react to cytokinin, e.g., by ENOD40 induction, CHS1:gusA and CHS2:gusA induction, fluorescence accumulation, and ccd (Table 2). This result suggests that only those cortical cells that respond to both auxin and cytokinin complete their cell cycle. This is consistent with findings that outer and inner cortex cells enter the cell cycle, but only inner cortical cells proceed through mitosis in alfalfa (Yang et al. 1994). In addition, the expression of ENOD40 in the cells responding to both auxin and cytokinin supports its role in ccd. The fact that outer cortical cells respond to cytokinin with ENOD40 expression and cell division in the determinate legume soybean (Yang et al. 1993) suggests that the sensitivity of either inner or outer cortical cells to cytokinin could determine the site of nodule initiation in indeterminate and determinate legumes, respectively. So far it is not known what could confer the sensitivity of certain cortical cells to cytokinin.

In Figure 3B we suggest a model in which parallel changes in auxin, cytokinin, and ENOD4O expression occur in nodule progenitor cells and act together in the induction of ccd. The

Fig. 3. Spatial and temporal patterns of expression of GH3:gusA, CHS3:gusA, flavonoid accumulation and ENOD40 expression and possible interactions between these responses during nodule formation in white clover. A, Diagrammatic summary of events during first $48 \mathrm{~h}$ post inoculation (p.i.) with $R$ hizobium leguminosarum bv. trifolii, as established by Mathesius et al. (1998a, 1998b) and this work. Patterns of four markers in root sections through site of spot inoculation with strain ANU843 are shown at different times after inoculation: auxin responsive promoter construct (GH3: gusA, gray), chalcone synthase CHS3:gusA construct (vertical lines), accumulation of a flavonoid compound (diagonal lines), and expression pattern of early nodulin gene ENOD40 (black). Key events of proposed signal transduction pathways are boxed and numbered, and correspond to boxed events shown in B. Nodule progenitor cells are first distinguished by their expression of CHS3:gusA (1), followed by flavonoid accumulation (2'), ENOD4O expression (3), and GH3:gusA expression (4). Cell divisions start at 40 to -48 h p.i. B, Proposed model of interactions of auxin, flavonoids, cytokinin, and ENOD40 during nodule initiation. Time course of reactions corresponds to A. Solid arrows symbolize (circumstantially) established reactions, dashed arrows symbolize proposed reactions. Upon stimulation by nodulating rhizobia, an inhibition of auxin transport occurs that results in symmetrical accumulation of auxin in all cortical cells at inoculation site. Simultaneously, flavonoid pathway is activated in nodule progenitor cells, resulting in accumulation of a flavonoid compound in the inner cortex. We propose that this flavonoid could change the auxin turnover in nodule progenitors, for example by regulating IAA (indole-3-acetic acid) oxidases, so that auxin levels remain sufficiently high in nodule progenitors to trigger ccd. In parallel, we propose that $R$. leguminosarum bv. trifolii affects cytokinin levels or sensitivity in the inner cortex, which leads to ENOD4O expression first detected in the pericycle and later in the inner cortical cells. Cells activated simultaneously by auxin, cytokinin, and ENOD4O proceed through mitosis. Nitrate is proposed to inhibit the modulation of cytokinin levels or sensitivity by R. leguminosarum bv. trifolii as well as the stimulatory effect of ENOD4O on cell division. Alternatively, nitrate could inhibit changes in the auxin levels or transport, and possible sites of inhibition (blocked arrows) are indicated. 
A

$\mathrm{Oh}$

$3 \mathrm{~h}$

5-10 h

$10-20 \mathrm{~h}$

$30 \mathrm{~h}$

40-48 h
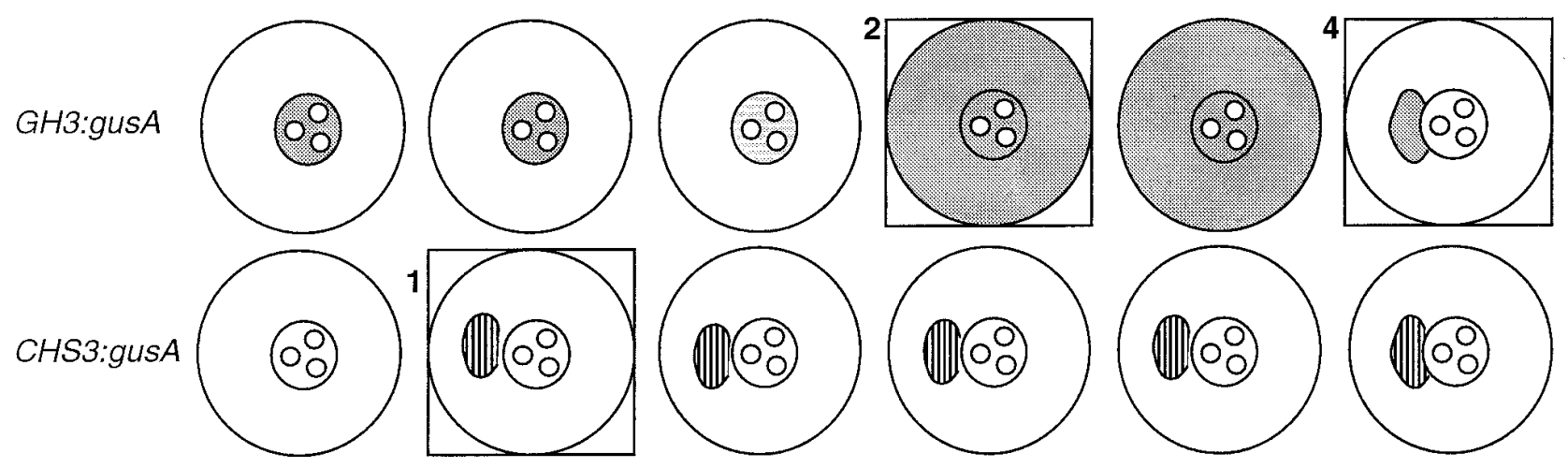

Flavonoids
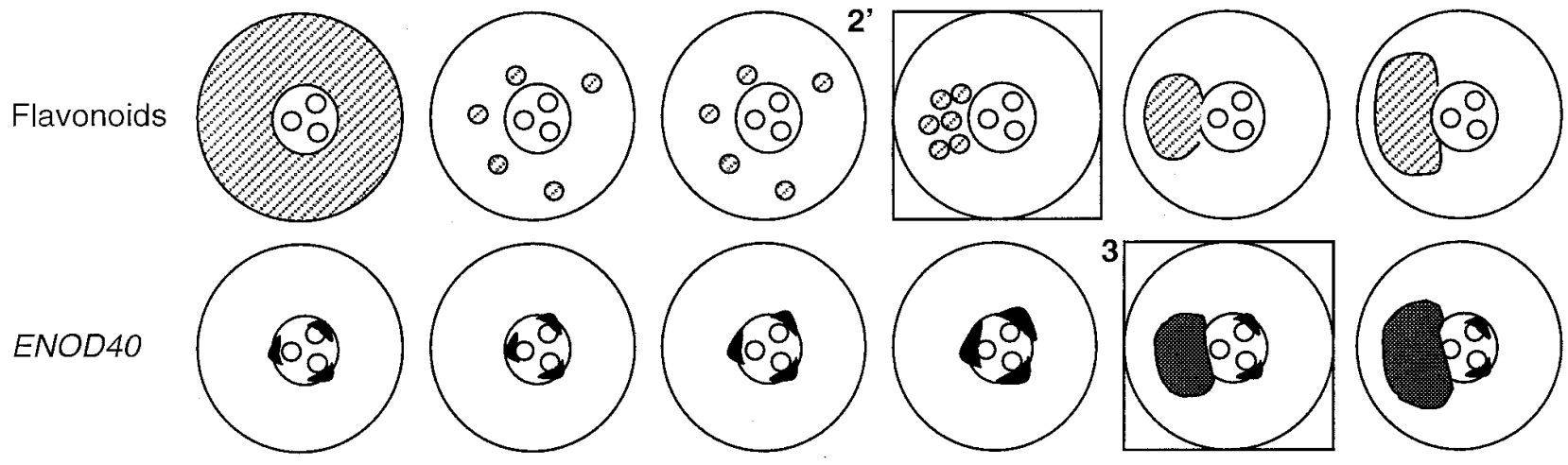

B

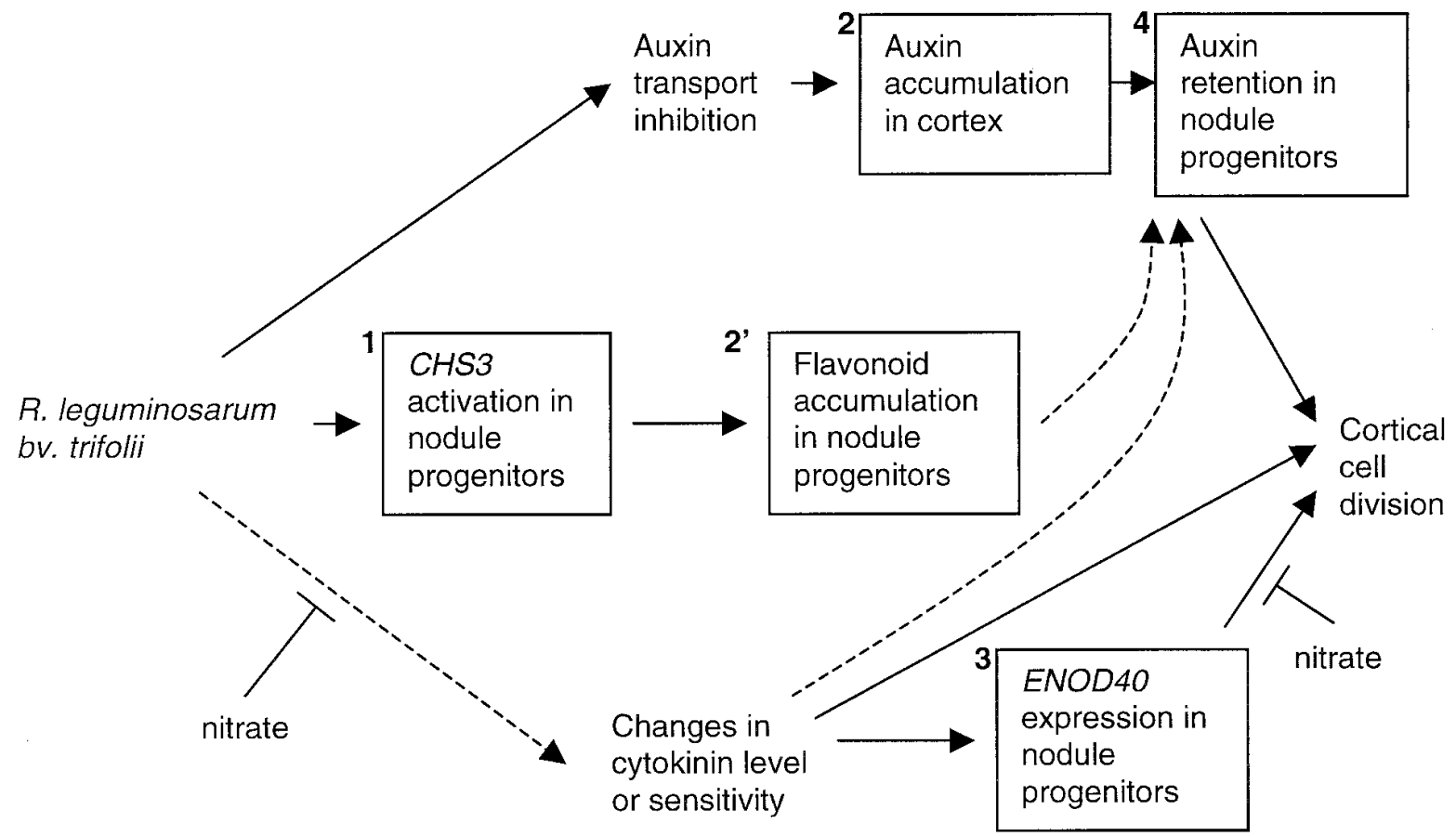


model also predicts that nitrate regulates changes in both auxin and cytokinin during nodulation.

\section{MATERIALS AND METHODS}

\section{Plant growth conditions and inoculations.}

White clover plants (Trifolium repens cv. Haifa) were grown as described elsewhere (Rolfe and McIver 1996; Mathesius et al. 1998a; b), under sterile nitrogen-free medium conditions in all experiments unless otherwise stated. Nitrate was added as $\mathrm{KNO}_{3}$ at $15 \mathrm{mM}$ to the medium where stated. Roots were spot inoculated as described in Mathesius et al. (1998b). Bacteria were grown in liquid Bergensen's Modified Medium (Rolfe et al. 1980) to early log phase at $28^{\circ} \mathrm{C}$ before inoculation. The strains used in this study were described previously (Mathesius et al. 1998a, 1998b).

\section{Application of plant growth regulators.}

The cytokinin 6-benzylaminopurine (BAP; Sigma Chemicals, St. Louis, MO), the auxin transport inhibitor NPA $(\alpha-$ naphthylphthalamic acid; gift of J. Katekar, CSIRO, Canberra), the auxin IAA (indole-3-acetic acid; Sigma Chemicals), and the ethylene precursor ACC (1-aminocyclopropane1-carboxylic acid; Sigma Chemicals) were used at concentrations of 1 to $100 \mu \mathrm{M}$. A stock solution of each compound (10 $\mathrm{mM}$ in ethanol) was diluted into warm $2 \%$ low melting point agarose (Progen, Darra, Australia) and poured into petri dishes. ACC was directly dissolved in water at $100 \mu \mathrm{M}$. Cubes of $2 \mathrm{~mm}$ side length (containing an equivalent of $8 \mu \mathrm{l}$ of each compound) were cut with a sterile razor blade and agarose blocks containing the different compounds were placed on roots of wild-type white clover rooted leaves at the zone of emerging root hairs. The final amount of each compound was $8 \times 10^{-12}$ to $8 \times 10^{-10}$ mol per block. Blocks were left on the roots for different incubation times under the described growth conditions. One root per plantlet was treated and a minimum of 20 plantlets were treated with each plant growth regulator.

\section{Sectioning, staining, and microscopy.}

Roots were embedded in 3\% low melting agarose (Progen, Darra, Australia) and sectioned $(200 \mu \mathrm{m})$ on a vibratome (BioRad, Hercules, CA). $\beta$-Glucuronidase (GUS) staining, detection of flavonoids in fresh roots sections, microspectrofluorometry, and photography were carried out as described previously (Mathesius et al. 1998a).

\section{Whole mount, in situ hybridization.}

The MsENOD40 DIG-labeled sense and antisense mRNA probes were prepared as described (Crespi et al. 1994). The MsENOD40 mRNA has very high homology (95\%) to TrENOD40 (EMBL no. TRJ00268) in the region used as a probe (nucleotides 30 to 430). The whole-mount, in situ hybridization protocol was adapted from Schmidt et al. (1996), and details are described below. For all solutions used for in situ hybridization, DEPC-treated water (1 $\mathrm{ml}$ of diethyl pyrocarbonate in 1 liter of water, stirred and autoclaved) was used to reduce the risk of contaminating the samples with RNases.

White clover wild-type roots of rooted leaves were spot inoculated with $R$. leguminosarum bv. trifolii or treated with hormone blocks at the zone of emerging root hairs. After dif- ferent inoculation times, a 3-mm segment around the inoculation site was embedded in agarose and sectioned $(200 \mu \mathrm{m}$ thickness) on a vibratome. Sections were placed in wells of a microtiter plate (Nunclon; Nalge Nunc International, Rochester, NY) containing PBS (130 mM NaCl, $10 \mathrm{mM} \mathrm{NaPO}, \mathrm{pH}$ 6.4) until all sections were cut. Sections were fixed in fixation buffer (containing PBS, $70 \mathrm{mM}$ EGTA, 4\% paraformaldehyde, $0.25 \%$ glutaraldehyde, $0.1 \%$ Tween $20,10 \%$ dimethyl sulfoxide [DMSO]) for $2 \mathrm{~h}$ at room temperature and washed (5 min each) in 50\% PBS/50\% methanol, twice in $100 \%$ methanol, three times in $100 \%$ ethanol, twice in methanol, and once in $50 \%$ methanol $/ 50 \%$ PBT (PBS plus $0.1 \%$ Tween 20 ). Fixation was repeated for $30 \mathrm{~min}$ in the described fixation buffer before the sections were washed five times in PBT and incubated with $10 \mathrm{mg}$ of proteinase $\mathrm{K}$ per $\mathrm{ml}$ (Boehringer Mannheim, Castle Hill, Australia) in PBT for $15 \mathrm{~min}$ at room temperature. Sections were washed twice in PBT containing $0.2 \%$ glycine and twice in PBT, refixed for $30 \mathrm{~min}$ in fixation buffer, and washed five times in PBT. This was followed by incubation for 15 min with $50 \% \mathrm{PBT} / 50 \%$ prehybridization solution (containing PBT, $50 \%$ deionized formamide, $0.33 \mathrm{M}$ $\mathrm{NaCl}, 50 \mathrm{mg}$ of heparin per $\mathrm{ml}$ ) and in $100 \%$ prehybridization solution at $42^{\circ} \mathrm{C}$ for $1 \mathrm{~h}$. Formamide (Sigma Chemicals) was deionized just before use by adding $5 \mathrm{ml}$ of AG 501-X8 resin (BioRad) to $100 \mathrm{ml}$ of formamide and gently shaking the mixture for $1 \mathrm{~h}$ under an $\mathrm{N}_{2}$ atmosphere.

The RNA probes were hydrolyzed up to 100 to $150 \mathrm{bp}$ (Crespi et al. 1994). The probes (sense and antisense, respectively) were heated for $5 \mathrm{~min}$ at $80^{\circ} \mathrm{C}$ after addition of $50 \mathrm{mg}$ of poly(A)RNA from yeast (Boehringer Mannheim), mixed with $4 \mathrm{ml}$ of prehybridization solution each and added to the sections. Most sections were incubated with the antisense probe, and about $10 \%$ of sections were used as sense controls. Hybridization took place at $42^{\circ} \mathrm{C}$ for $16 \mathrm{~h}$. Sections were washed for $1 \mathrm{~h}$ at $42^{\circ} \mathrm{C}$ with prehybridization solution, then once with $50 \%$ prehybridization solution $/ 50 \%$ PBT at room temperature and four times with PBT $(\mathrm{pH} 7.5)$. RNaseA (Boehringer Mannheim; $50 \mathrm{mg} / \mathrm{ml}$, in a buffer containing 10 $\mathrm{mM}$ Tris- $\mathrm{HCl}, 5 \mathrm{mM}$ EDTA, $0.5 \mathrm{mM} \mathrm{NaCl}$ ) was added for 30 min of incubation at $37^{\circ} \mathrm{C}$. Sections were washed four times for 15 min each in PBT.

In the following procedure, half of the sections were treated with an alkaline phosphatase (AP)-conjugated anti-DIG antibody, the other half with an FITC (fluorescein)-labeled antiDIG antibody. These two different antibodies were used to ensure that the resulting staining patterns were due to sites of hybridization and not a result of artefacts of one particular antibody detection method.

\section{AP-antibody binding and staining.}

For pre-adsorption, the AP-conjugated antibody (Boehringer Mannheim) was diluted 1:500 in PBT containing $50 \mathrm{mg}$ of bovine serum albumin (BSA) per $\mathrm{ml}$ and $25 \mathrm{mg} / \mathrm{ml}$ of a root extract from white clover, and incubated for $30 \mathrm{~min}$ at room temperature to decrease nonspecific binding of the antibodies. The root extract was obtained by freezing roots of white clover in liquid nitrogen, grinding them to a fine powder, and extracting the powder in acetone. The acetone extract was evaporated and the remaining material was suspended in PBT. The pre-adsorbed antibody was then briefly centrifuged to remove the insoluble root extract and diluted 1:5 in PBT 
containing $50 \mathrm{mg}$ of BSA per $\mathrm{ml}$. The sections were incubated with the antibody mixture for $1 \mathrm{~h}$ at room temperature and then washed five times in PBT $(\mathrm{pH} 7.5)$ and once in staining buffer (containing $100 \mathrm{mM} \mathrm{NaCl}, 5 \mathrm{mM} \mathrm{MgCl}, 100 \mathrm{mM}$ Tris- $\mathrm{HCl}$ [pH 9.5] and $0.1 \%$ Tween 20). To inhibit endogenous AP activity, sections were incubated for $10 \mathrm{~min}$ with staining buffer containing $1 \mathrm{mM}$ levamisole (L [-] 2,3,5,6tetrahydro-6-phenylimidazo [2,1-b] thiazolehydrochloride; Sigma Chemicals) and washed again with staining buffer. For the staining reaction, $9 \mu \mathrm{l}$ of NBT (4-nitroblue tetrazolium chloride, $75 \mathrm{mg}$ of stock in $70 \%$ [vol/vol] water/dimethylformamide) per $\mathrm{ml}$, and $7 \mu \mathrm{l}$ of BCIP (5-bromo-4-chloro-3indolylphosphate, $50 \mathrm{mg}$ of stock in $100 \%$ demethylformamide [both from Boehringer Mannheim]) per ml were added to the staining solution, and the sections were incubated in the solution in the dark for several hours until purple staining occurred. To stop the reaction, PBT containing $10 \mathrm{mM}$ EDTA was added. Sections were transferred to glass slides and examined under a light microscope.

\section{FITC-antibody binding and staining.}

For the FITC-labeled anti-DIG antibody, the Fluorescent Antibody Enhancer Set for DIG Detection (Boehringer Mannheim) was used and the manufacturer's protocol followed. Green FITC fluorescence was detected in root sections with an excitation filter (maximum excitation at $495 \mathrm{~nm}$ ) and a dichroic mirror (excluding emission above $505 \mathrm{~nm}$ ) on an Optiphot epifluorescence microscope (Nikon, Tokyo). The same filters were used to analyze the sense control sections.

\section{ACKNOWLEDGMENTS}

U. M. was supported by an Overseas Postgraduate Research Scholarship by the Australian Government. Part of the work was supported by a grant to B. G. R. from the French Embassy to Australians working collaboratively in France.

\section{LITERATURE CITED}

Arora, N., Skoog, F., and Allen, O. N. 1959. Kinetin-induced pseudonodules on tobacco roots. Am. J. Bot. 46:610-613.

Asad, S., Fang, Y., and Hirsch, A. M. 1994. Isolation and characterisation of cDNA and genomic clones of MsENOD40; transcripts are detected in meristematic cells of alfalfa. Protoplasma 183:10-23.

Bauer, P., Ratet, P., Crespi, M. D., Schultze, M., and Kondorosi, A. 1996. Nod factors and cytokinins induce similar cortical cell division, amyloplast deposition and Msenod12A expression in alfalfa roots. Plant J. 10:91-105.

Boot, K. J. M., van Brussel, A. A. N., Tak, T., Spaink, H. P., and Kijne, J. W. 1999. Lipochitin oligosaccharides from Rhizobium leguminosarum bv. viciae reduce auxin transport capacity in Vicia sativa subsp. nigra roots. Mol. Plant-Microbe Interact. 12:839-844.

Charon, C., Johansson, C., Kondorosi, E., Kondorosi, A., and Crespi, M. 1997. ENOD40 induces dedifferentiation and division of root cortical cells in legumes. Proc. Natl. Acad. Sci. USA 94:8901-8906.

Charon, C., Sousa, C., Crespi, M., and Kondorosi, A. 1999. Alteration of enod40 expression modifies Medicago truncatula root nodule development induced by Sinorhizobium meliloti. Plant Cell 11:1953-1965.

Cooper, J. B., and Long, S. R. 1994. Morphogenetic rescue of Rhizobium meliloti nodulation mutants by trans-zeatin secretion. Plant Cell 6:215-225.

Corich, V., Goormachtig, S., Lievens, S., Van Montagu, M., and Holsters, M. 1998. Patterns of ENOD40 gene expression in stem-borne nodules of Sesbania rostrata. Plant Mol. Biol. 37:67-76.

Crespi, M. D., Jurkevitch, E., Poiret, M., d'Aubenton-Carafa, Y., Petrovics, G., Kondorosi, E., and Kondorosi, A. 1994. ENOD40, a gene expressed during nodule organogenesis, codes for a nontranslatable RNA involved in plant growth. EMBO J. 13:5099-5112.

Dehio, C., and deBruijn, F. J. 1992. The early nodulin gene SrEnod2 from Sesbania rostrata is inducible by cytokinin. Plant J. 2:117-128.

Fang, Y., and Hirsch, A. M. 1998. Studying early nodulin gene ENOD4O expression and induction by nodulation factor and cytokinin in alfalfa. Plant Physiol. 116:53-68.

Hare, P. D., and van Staden, J. 1997. The molecular basis of cytokinin action. Plant Growth Reg. 23:41-78.

Hirsch, A. M. 1992. Developmental biology of legume nodulation. New Phytol. 122:211-237.

Hirsch, A. M., and Fang, Y. 1994. Plant hormones and nodulation: What's the connection? Plant Mol. Biol. 26:5-9.

Hirsch, A. M., Fang, Y., Asad, S., and Kapulnik, Y. 1997. The role of phytohormones in plant-microbe symbioses. Plant Soil 194:171-184.

John, P. C. L., Zhang, K., Cong, C., Diederich, L., and Wightman, F. 1993. p34cdc2 related proteins in control of cell cycle progression, the switch between division and differentiation in tissue development, and stimulation of division by auxin and cytokinin. Aust. J. Plant Physiol. 20:503-526.

Kouchi, H., and Hata, S. 1993. Isolation and characterisation of novel nodulin cDNAs representing genes expressed at early stages of soybean nodule development. Mol. Gen. Genet. 238:106-119.

Kouchi, H., Takane, K., So, R. B., Ladha, J. K., and Reddy, P. M. 1999. Rice ENOD40: Isolation and expression analysis in rice and transgenic soybean root nodules. Plant J. 18:121-129.

Lerouge, P., Roche, P., Faucher, C., Maillet, F., Truchet, G., Promé, J.C., and Dénarié, J. 1990. Symbiotic host specificity of Rhizobium meliloti is determined by a sulphated and acylated glucosamine oligosaccharide signal. Nature 344:781-784.

Libbenga, K. R., van Iren, F., Bogers, R. J., and Schraag-Lamers, M. F. 1973. The role of hormones and gradients in the initiation of cortex proliferation and nodule formation in Pisum sativum L. Planta 114:2939.

Mathesius, U., Bayliss, C., Weinman, J. J., Schlaman, H. R. M., Spaink, H. P., Rolfe, B. G., McCully, M. E., and Djordjevic, M. A. 1998a. Flavonoids synthesized in cortical cells during nodule initiation are early developmental markers in white clover. Mol. Plant-Microbe Interact. 11:1223-1232.

Mathesius, U., Schlaman, H. R. M., Spaink, H. P., Sautter, C., Rolfe, B. G., and Djordjevic, M. A. 1998b. Auxin transport inhibition precedes nodule formation in white clover roots and is regulated by flavonoids and derivatives of chitin oligosaccharides. Plant J. 14:23-34.

Mathesius, U., Weinman, J. J., Rolfe, B. G., and Djordjevic, M. A. 2000. Rhizobia can induce nodules in white clover by "hijacking" mature cortical cells activated during lateral root development. Mol. PlantMicrobe Interact. 13:170-182.

Matvienko, M., van de Sande, K., Yang, W. C., van Kammen, A., and Bisseling. T. 1994. Comparison of soybean and pea ENOD40 cDNA clones representing genes expressed during both early and late stages of nodule development. Plant Mol. Biol. 26:487-493.

Minami, E., Kouchi, H., Cohn, J. R., Ogawa, T., and Stacey, G. 1996. Expression of the early nodulin, ENOD40, in soybean roots in response to various lipo-chitin signal molecules. Plant J. 10:23-32.

Papadopoulou, K., Roussis, A., and Katinakis, P. 1996. Phaseolus ENOD40 is involved in symbiotic and non-symbiotic organogenesis processes: Expression during lateral root and nodule development. Plant Mol. Biol. 30:403-417.

Relic, B., Perret, X., Estrada-Garcia, M. T., Kopcinska, J., Golinowski, W., Krishnan, H., Pueppke, S. G., and Broughton, W. J. 1994. Nod factors of Rhizobium are the key to the legume door. Mol. Microbiol. 13:171-178.

Rodriguez-Barrueco, C., and Bermudez de Castro, F. 1973. Cytokinininduced pseudonodules on Alnus gluticosa. Physiol. Plant. 29:277280.

Rolfe, B. G., Gresshoff, P. M., and Shine, J. 1980. Rapid screening for symbiotic mutants of Rhizobium and white clover. Plant Sci. Lett. 19: 277-284.

Rolfe, B. G., and McIver, J. 1996. Single-leaf plantlet bioassays for the study of root morphogenesis and Rhizobium nodulation. Aust. J. Plant Physiol. 23:271-283.

Schmidt, E. D. L., van Hengel, A. J., and de Vries, S. C. 1996. A rapid method for localising cell-specific transcripts in plant cell cultures. Biochemica 4:25-28. 
Schneider, E. A., and Wightman, F. 1974. Metabolism of auxin in higher plants. Annu. Rev. Plant Physiol. 25:487-513.

Schultze, M., and Kondorosi, A. 1998. Regulation of symbiotic root nodule development. Annu. Rev. Genet. 32:33-57.

Taniguchi, M., Kiba, T., Sakakibara, H., Ueguchi, C., Mizuno, T., and Sugiyama, T. 1998. Expression of Arabidopsis response regulator homologs is induced by cytokinins and nitrate. FEBS Lett. 429:259262.

van de Sande, K., Pawlowski, K., Czaja, I., Wieneke, U., Schell, J., Schmidt, J., Walden, R., Franssen, H., and Bisseling, T. 1996. Modification of phytohormone response by a peptide encoded by ENOD4O of legumes and a non legume. Science 273:370-373.

Vijn, I., Yang, W. C., Pallisgard, N., Jensen, E. O., van Kammen, A., and Bisseling, T. 1995. VsENOD5, VsENOD12 and VsENOD40 expression during Rhizobium-induced nodule formation on Vicia sativa roots. Plant Mol. Biol. 28:1111-1119.
Yang, W. C., de Blank, C., Meskiene, I., Hirt, H., Bakker, J., van Kammen, A., Franssen, H., and Bisseling, T. 1994. Rhizobium Nod-factors reactivate the cell cycle during infection and nodule primordium formation, but the cell cycle is only completed in the primordium formation. Plant Cell 6:1415-1426.

Yang, W. C., Katinakis, P., Hendriks, P., Smolders, A., de Vries, F., Spee, J., van Kammen, A., Bisseling, T., and Franssen, H. 1993. Characterisation of GmENOD40, a gene showing novel patterns of cell-specific expression during soybean nodule development Plant J. 3:573-585

Zhang, H., Jennings, A., Barlow, P. W., and Forde, B. 1999. Dual pathways for regulation of root branching by nitrate. Proc. Natl. Acad. Sci. USA 96:6529-6534.

Zhang, K., Letham, D. S., and John, P. C. L. 1996. Cytokinin controls the cell cycle at mitosis by stimulating the tyrosine dephosphorylation and activation of p34 ${ }^{\text {cdc2 }}$-like H1 histone kinase. Planta 200:2-12. 